\title{
A MÚSICA AMERÍNDIA COMO MITOLÓGICA: POR QUE CANTAM OS KISÊDJÊ?
}

EVANDRO DE SOUSA BONFIM ${ }^{1}$

CEBRAP

\section{RESENHA}

SEEGER, Anthony. Por que cantam os Kisêdjê? São Paulo: Cosac\&Naify, 2015. 320p.

O lançamento da versão brasileira de Por que cantam os Kisêdjê? traz ao público de língua portuguesa uma obra antropológica fundamental, tanto para a etnomusicologia, quanto para a etnologia ameríndia. No que diz respeito à etnomusicologia, o autor, Anthony Seeger, oferece não a análise formal, centrada em produtos musicais de grupos tradicionais, mas a discussão mais ampla sobre o lugar da música na vida de um povo - no caso, os Kisêdjê, também conhecidos como Suyá, que integram o tronco Linguístico Macro-Jê e atualmente habitam o Parque do Xingu.

Para Seeger, além das propriedades acústicas singulares, se faz necessário responder às questões que vão contextualizá-las socialmente, a saber o que, quem, quando, onde, como, para quem e por que acontece a música, entendida primordialmente como o canto entre os Kisêdjê. Tal canto não está dissociado de todos outros sons que a captação focal

\footnotetext{
${ }^{1}$ Doutor em Antropologia Social pela Universidade Federal do Rio de Janeiro (PPGAS-MN/UFRJ). Bolsista de Pós-Doutorado da Fundação de Amparo à Pesquisa do Estado de São Paulo (FAPESP). E-mail: evandrobonfim@ hotmail.com .
} 
consideraria acidental: gritos, imitações de animais, ruídos cotidianos tudo faz parte da orquestração sonora do canto indígena. Assim, a obra se torna valiosa tanto pela análise, quanto pela proposição de um método para a etnomusicologia que não desembarace as tramas sociais das expressões sonoras, devidamente registradas no DVD que encarta a obra.

No tocante à etnologia ameríndia, o autor estabelece a música como força cosmológica, capaz de estabelecer e recriar as relações sociais dos Kisêdjê a partir da dinâmica entre elementos próprios dos povos Jê, como os sistemas de metade, os grupos etários, as atribuições onomásticas e as potências exteriores, sob a forma de aliados, inimigos, e, sobretudo, animais. Assim, a música, na obra, se torna um código das injunções entre natureza e cultura, à semelhança dos códigos culinários e astronômicos apresentados nas Mitológicas; através, justamente, das comparações entre as propriedades da música e do mito. É a partir da música como elemento importante para a etnologia ameríndia e da proposta inovadora de investigação em etnomusicologia que a resenha destacará alguns dos principais pontos do trabalho de Seeger.

No capítulo 1, o autor nos apresenta a Festa do Rato, o principal ritual de iniciação kisêdjê, tal como ocorrera em 1972. Embora a ênfase da festividade esteja nos cantos-chamado individuais, que os homens dirigem aos que serão seus receptores de nomes, Seeger nota que as performances dizem respeito ao fundamento relacional que constitui a vida indígena. Estão incluídas a distribuição de alimentos; as relações de parentesco, sobretudo entre o homem e a irmã; as relações rituais entre os agora adultos e seus doadores de nomes; e mesmo as relações mais amplas, como entre grupos onomásticos, as metades, outras aldeias, outras etnias, os animais, as árvores, os espíritos e os ancestrais mitológicos, sendo os últimos os grandes compositores da música kisêdjê. $O$ ápice da festa, que dura cerca de duas semanas e concentra as atividades ao entardecer, é a aparição das máscaras de animais, com destaque para o rato, confeccionadas com a madeira do buriti. Para o autor, a vida ritual é um modo de existência kisêdjê que se alterna com a temporalidade cotidiana, focada nas relações familiares imediatas e tarefas solitárias.

O entendimento sobre a música, entendida primordialmente como canto, conforme mostra o capítulo 2, depende do seu lugar no sistema 
de artes verbais que inclui as instruções, nas quais se encontram as narrações mitológicas, as invocações destinadas principalmente à cura (sangere) e as falas em geral (kapere). Todas as formas vocais guardam características particulares, diferenciando-se no que diz respeito aos enunciadores, ao local de realização (se em público ou para efeitos domésticos) e ao registro linguístico, variando, sobretudo, em termos de fonação (como o sopro nas invocações), de ritmo da fala e da utilização de arcaísmos. Alguns elementos são, no entanto, compartilhados, como os paralelismos, a ocorrência de componentes intraduzíveis, mas plenos de sentido, e a existência de demarcadores prosódicos indicando a posição do falante. Por exemplo, jovens não podem usar a entonação vigorosa correspondente a bons caçadores ou guerreiros. Os cantos, nas modalidades de canto-chamado e canto em uníssono, representam o polo mais estruturado, com menor possibilidade de intervenções e com maior grau de alteridade linguística dentro do sistema de artes verbais, que possui a fala cotidiana como o elemento menos musical. Nos cantos, a linha melódica prevalece sobre a letra, cedendo lugar ao puro material fonológico, como sílabas, que, associadas a notas musicais, podem remeter à fala das onças, das abelhas e de inimigos mortos, os únicos capazes de recuperar o pleno sentido das canções.

O capítulo 3 mostra que todos os cantos kisêdjê são provenientes de fora do grupo e estão relacionados à questão da metamorfose. Muitos foram ensinados nos tempos míticos por personagens em processo de transformação em animais. Já os "compositores" indígenas mais atuais são pessoas que tiveram o espírito capturado por feiticeiros como forma de castigo, causando o adoecimento. Os espíritos apartados dos corpos são colocados para viver com animais, onde ouvem os cantos próprios de cada espécie. Através dos sonhos, o indígena sem espírito pode ensinar novo cantos de origem animal para os demais kisêdjê. Atualmente, os cantos dos animais estão sendo substituídos pelos cantos aprendidos com outros povos indígenas outrora e com os brancos, substituindo os animais como importante figura de alteridade. A aprendizagem dos cantos, segundo Seeger, significa a apreensão de novos conhecimentos e constitui o principal eixo relacional entre a natureza e a sociedade, em conjunto com a preparação dos alimentos, conforme a tese das Mitológicas. 
No capítulo 4, o autor apresenta a aldeia kisêdjê como uma grande sala de concertos, marcada pela transparência acústica. $O$ segredo está relacionado ao silêncio, e não ao que está oculto da visão, pois a vida pública se faz pela propagação das expressões sonoras que penetram todas as casas. É o som, aliás, que compõe os círculos concêntricos que configuram a espacialidade do grupo Jê: no centro, os cantos em uníssonos masculinos; nas casas circundantes, cantos individuais e os barulhos domésticos; no espaço liminar após as casas, o silêncio exigido pelas atividades fortuitas - silêncio também presente nas roças, geralmente frequentadas por espíritos. O som retorna na floresta, lugar onde humanos se metamorfoseavam, aprendendo os cantos dos animais, bem como as manifestações sonoras dos seres da mata e de inimigos.

O tempo também obedece a uma divisão sonora, sendo o ano dividido entre canções da chuva e canções da seca e o dia marcado pelo ritmo de cantos coletivos, do silêncio doméstico, de cantos individuais, de novos cantos coletivos e do silêncio dos segredos. Entremeados com tais cantos estão os cantos das grandes e pequenas festividades, que, em conjunto, são percebidas como uma única grande peça musical de movimentos interligados. Os próprios Kisêdjê, divididos pelas metades, por grupos etários e pelo sexo, formariam os diversos naipes de uma orquestra, contribuindo com tipos de sons distintos para os eventos musicais, que devem ser captados não apenas através dos cantos principais, mas também de todos os ruídos, das imitações de animais, dos lamentos, enfim, de todos os outros sons considerados acidentais para a etnomusicologia tradicional. Já os instrumentos musicais são os próprios corpos dos indígenas, o que se comprova pela não adoção de instrumentos xinguanos e a orientação da estética kisêdjê: os discos bocais e auriculares enfatizam a experiência aural.

Seeger também ressalta a importância da descrição das propriedades formais da música indígena, mostrando, no capítulo 5 , que elementos aparentemente técnicos, como a recorrente ascendência da afinação tonal, são expressões acústicas de concepções fundamentais sobre o canto masculino. A chave está no abaixamento máximo da laringe, que identifica a potência vocal masculina, em contraposição ao canto feminino e as imitações juvenis. Os momentos de afinação ascendente relacionam-se com seções da canção em que novos nomes 
são citados. Como não há regente, as variações dependem da longa aprendizagem e da percepção de demarcadores prosódicos, vocalizados pelo especialista ritual geralmente na mais completa escuridão, o que reforça o apuro auditivo. Sustentar tal gesto laríngeo implica em força e resistência, atributos celebrados dos homens adultos. Como em outros grupos Jê, a plenitude da pessoa e o ideal estético estão interligados (como na importância da cor vermelha para os Xavante), sendo que os mais velhos apresentam a garganta mais "bela": possante, com maior ressonância e que oferece a frequência fundamental para a afinação do coro que ascende com a participação dos mais jovens.

No capítulo 6, tem-se, por fim, a descrição cronológica da festa, iniciando-se com os preparativos, a saber, a colheita e o beneficiamento dos brotos de buriti, que vão servir de matéria-prima para a confecção da máscara básica. Também se assiste à progressiva participação dos cantores, com o empenho do solista sendo, aos poucos, apoiado com o crescente adensamento do coro. Igualmente, intensificam-se as expedições, tanto para o sustento dos principais participantes da festa, quanto para atender aos convidados, sobretudo afins casados com mulheres kisêdjê, conferindo à cerimônia um caráter multiétnico. Depois, começam as visitas de ornamentação das máscaras, realizadas pelos amigos formais. Cada detalhe da máscara deve corresponder ao grupo onomástico, e as metades cerimoniais correspondentes a quem vai usar o artefato. Outro elemento importante é padrão de pintura corporal, tendo como base, na maioria dos casos, um grande campo vermelho com detalhes em preto, mas também em branco, junto com penas de papagaio e enfeites de buriti.

Depois se segue a sequência ritual, com as casas apinhadas de cantores, que saem com ordem preestabelecida até a casa dos homens e, depois, até o acampamento na floresta. O percurso tem um caráter iniciático, passando do mais doméstico ao desconhecido, ou seja, do abandono da casa materna rumo ao pleno mundo masculino. A comida integra parte importante do processo, pois o preparo doméstico, cozido, feito por mães e irmãs, é substituído pela carne assada, preparada pelos demais participantes. A sensação descrita por Seeger é de uma plenitude de vozes tomando conta de todos os espaços, nos mais diversos tipos de encontros e desencontros audíveis, formando o que autor chama de 
"apoteose". Faz parte do fulgor apoteótico a pantomima dos palhaços, geralmente idosos, que exageram os achaques da idade para causar $o$ risível e o grotesco que o momento exige. Nos momentos posteriores, não apenas os meninos, mas todos os homens entram na justaposição entre tempo mítico e festivo. O corpo se afeta pela dança. E a liminaridade, diferente das marcas visuais tão bem descritas por Van Gennep e Tuner, torna-se a das marcas audíveis - pois as máscaras não são vistas no escuro, mas somente os grunhidos, os saldos, os esgares das transformações dos ratos nos tempos míticos que iniciaram a civilização do milho, manifesto no próprio espírito do rato (mekarô) a ocupar os participantes. A festa se encerra após 14 dias, com a invasão do pátio e a humanização dos ratos através de banhos de água fria e flechadas nas máscaras, providenciados pelas mulheres, para abater os grupos onomásticos. No entanto, sempre se corre o risco de transformações irreversíveis.

Assim, Por que cantam os Kisêdjê? excede em muito a etnomusicologia. O foco é o significado da música para o grupo Jê, e, nesse tocante, Seeger se iguala a Levi-Strauss quando o francês elege, nas Mitológicas, a culinária e a astronomia como códigos que servem de matéria-prima conceitual e vívida para se aceder à lógica do pensamento ameríndio, movimento para o qual se vale das propriedades formais da música, sobretudo a wagneriana. Seeger faz o mesmo com a música. Mostra como elementos formais, como a subida da afinação do canto coral, têm a ver com a noção de estética e do que significa ser humano para os Kisêdjê. Nesse sentido, quaisquer imprecisões que o autor tenha cometido com questões linguísticas, conforme apontam resenhas que tocam apenas o rés-do-chão da obra, parecem de somenos importância diante da proficuidade e riqueza dessa peça etnográfica que ainda ecoa a melodia dos primeiros tempos. "Os Kisêdjê cantam porque, pelo canto, conseguiam restaurar certos tipos de ordem em seu mundo, e nele criar outros tipos de ordem também".

\section{Referência bibliográfica}

SEEGER, Anthony. Por que cantam os Kisêdjêe? São Paulo: Cosac\&Naify, 2015. 
Recebido em: 01/11/2017 * Aprovado em: 23/11/2017 * Publicado em: 31/12/2017 